\title{
How Mental Health Clinicians Can Address Issues of Diversity with Incarcerated Individuals
}

\author{
Eman Tadros, M.S. MFT ${ }^{1}$ \\ ${ }^{1}$ The University of Akron, United States \\ Correspondence: Eman Tadros, M.S. MFT, The University of Akron, 344 Village Pointe Dr., D, Akron, OH 44313, \\ United States.
}

Received: August 15, 2018

Accepted: August 29, $2018 \quad$ Available online: August 30, 2018

doi:10.11114/ijsss.v6i9.3536

URL: https://doi.org/10.11114/ijsss.v6i9.3536

\begin{abstract}
Mental Health Clinicians are accustomed to being confronted with not only difficult situations, but difficult conversations. Although discussing issues of diversity can be challenging, these dialogues are vital to the therapeutic process. In order to work under a multicultural framework, a clinician must minimally have basic knowledge on the culture of the client(s) being treated. Therapists are to use culturally appropriate intervention strategies and be mindful of the rules of the client's culture. It is advised to work with the client(s) to define their culture, what it means to them, and what it means to society. It is the duty of a clinician to exemplify this for clients and give clients the power, permission, and invitation that they may believe they need, to do the same. This article discusses issues of diversity in the incarcerated system, clarifies the clinician's role, and empowers clinicians to utilize multicultural techniques in treatment.
\end{abstract}

Keywords: counseling, incarceration, issues of diversity, multiculturalism, prison, therapy

\section{Issues of Diversity in the Incarcerated System}

The incarcerated population is underserved in the world of mental health. In 2014 according to the U.S. Department of Justice- Bureau of Justice Statistics, an estimated 6,851,000 adults were incarcerated (Kaeble, Glaze, Tsoutis, \& Minton, 2015). Some mental health issues have shown to be an effect of racial discrimination (Carter, Lau, Johnson, \& Kirkinis, 2017). Although, while incarcerated the physical health of individuals usually improve, it is common for their mental health to decline (Wildeman \& Wang, 2017). The problematic task at hand for clinicians is to combine knowledge of prison culture with mental health and issues of diversity (Kapoor, Dike Burns, Carvalho, \& Griffith, 2013).

In the book The New Jim Crow: Mass Incarceration in the Age of Colorblindness, Michelle Alexander discusses the McClesky v Kemp case (2010). In this case racial bias facilitated law enforcement's excessive traffic stops. These stops were used as probable cause to unfairly target ethnic minorities in the war on drugs. Petitioners claimed the actions in this case was going against the fourth amendment right of all U.S. citizens. Courts explained that whether or not law enforcement made the decision based on race their behavior is still considered to be "reasonable" (Alexander, 2010). Therefore, the courts deemed racial bias by law enforcement is be tolerated.

\section{The Clinician's Role in this System}

Due to the increasing numbers of minority populations in the U.S., it is inevitable that clinicians will treat clients of a difference race than their own (Remley \& Herlihy, 2010; Trahan \& Lemberger, 2014). To be successful in acquiring culturally competencies, the clinician must first have basic knowledge about not only different ethnic cultures, but also, prison culture (Kapoor et al, 2013).

Interviews were conducted to exemplify racism and discrimination exhibited by prisoners of color. It was found that correction offers were major offenders of discrimination against prisoners of color (Katz, Willis, \& Joseph, 2014). The role of a clinician is to not mirror the unjust thoughts, actions, and beliefs that other professionals in this setting bestow onto these individuals. Ethical issues in relation to multicultural counseling is most prevalent in lack of competence (Pack-Brown, Thomas, \& Seymour, 2008; Trahan \& Lemberger, 2014). Therefore, cultural competence is a necessity when working with the diverse, incarcerated population (Tadros \& Finney, 2018).

Defining normal family development can be an additional layer of complexity when a member of the family system is incarcerated. What constitutes as normal family development anyway? Historically, treatment has been based off of 
western norms and ideologies. Thus, the issue here is administering treatment from the perspective of the clinician, rather than the worldview of the client(s). Thus, cultural competency requires the clinician to implement this information flexibly as needed, always with the best interest of the client in mind (Kapoor et al, 2013).

Researchers Marbley, Wimberly, Berg, Rouson, \& Wilkins (2011) have discussed their experiences in working with African American families and promoted collaboration between clinician and client(s). Coming from a collaborative stance, instead of the clinician being deemed the expert, allows the clinician and client to work together towards a common goal. Researchers suggested that clinicians should not be scared to discuss culture, beneficially use the stories clients bring into treatment, and provide insight on the impacts of that culture and how it effects their lives and the therapeutic relationship (Marbley et al, 2011).

\section{Empowering Clinicians to Utilize Multicultural Techniques in Treatment}

To work under a multicultural framework, a clinician must at least have some basic knowledge on the culture of the client(s) they are working with (Tadros \& Finney, 2018). Clinicians are to use culturally appropriate intervention strategies and be mindful of the rules of the client's culture. For example, a family's rules might be governed by a religious or ethnic concept, therefore, pathologizing an interaction would be detrimental to the therapeutic relationship, the client(s), and overall treatment (Tadros \& Finney, 2018). At times, clinicians may engage in unethical behavior that may cause harm to the client (Remley \& Herlihy, 2010; Trahan \& Lemberger, 2014). Due to the lack of awareness some clinicians may have of their own biases, they may not notice the implications this has on their clients (Trahan \& Lemberger, 2014).

Sue differentiates ineffective and effective strategies for clinicians. Ineffective strategies include first, doing nothing"lack of actions model that race talk should be avoided" (Sue, 2015, p. 231). He also suggests not to sidetrack the conversation as this eliminates the clinician's credibility. He advises against appeasing the clients because, as he explains, "the problem with the maintenance of harmony is that it negates deeper exploration of biases and stereotypes, and nested emotions associated with race and racism" (Sue, 2015, p. 233). Terminating the discussion and becoming defensive although common mistakes, are also shown to be counterproductive.

Instead of utilizing the above strategies, Sue suggests more efficient techniques. He recommended that the clinician understands the client's racial/ cultural identity (Sue, 2015). Despite the immense difficulty in being able to do so, he recommended acknowledging and admitting one's racial biases. This has shown to be difficult as sometimes individuals are unaware of these biases and carry out racial microaggressions subconsciously. He advocated for the clinician to be comfortable and open to discussing topics of race and racism (Sue, 2015). However, our society has seemed to devalue these discussions in many institutions such as schools and the workplace. The challenge for clinicians is to be comfortable with the uncomfortable.

Further, it is suggested to understand the meaning of emotions and validate and facilitate discussions of feelings (Sue, 2015). This seems a bit more manageable and commonplace for an individual trained to be a therapist, psychologist, counselor, social worker, etc. Similarly, the next recommendation is to control the process, not the content of race talk. Clinically, mental health professionals are trained to 'double listen' and gracefully keep track of the shift between content to process. Sue challenged clinicians to unmask the difficult dialogue through process observations and interventions as well as to not allow for this dialogue to be brewed in silence (Sue, 2015). This means clinicians are to check in with clients on their thoughts and feelings before, during, and after these discussions. Finally, he advised to understand differences in communication styles and forewarn, plan, and purposefully instigate race talk (Sue, 2015).

A clinician is to facilitate discussions surrounding feelings of oppression, gender roles, and racism. The benefit of these discussions is to foster understanding of their worldview as well as teaching the client(s) how to create their own social location. Multicultural clinicians are to become educated of their own cultural values and beliefs; they must be aware of their own and their client's worldview. They are encouraged to participate in self- exploration through therapy, discussions, and reading relevant of literature.

Techniques and interventions used in treatment for individuals and families should derive from previous knowledge and cultural observation from the viewpoint of the client(s) (Marbley, Wimberly, Berg, Rouson, \& Wilkins, 2011). By incorporating cultural competencies into clinician's training, they are displaying the importance of this inclusion. Multicultural competency isn't an additional subspecialty or a bonus, it should be integrated into treatment regardless of population, facility, clinician, or theoretical orientation. The hope and purpose of this article is to highlight the importance of issues of diversity and empower clinicians to discuss these issues to better serve their incarcerated clients.

\section{References}

Alexander, M. (2010). The New Jim Crow: Mass Incarceration in the Age of Colorblindness. New York: New Press.

Carter, R. T., Lau, M. Y., Johnson, V., \& Kirkinis, K. (2017). Racial Discrimination and Health Outcomes Among 
Racial/Ethnic Minorities: A Meta-Analytic Review. Journal of Multicultural Counseling \& Development, 45(4), 232-259. https://doi.org/10.1002/jmcd.12076

Chan, C. D., Cor, D. N., \& Band, M. P. (2017). Privilege and Oppression in Counselor Education: An Intersectionality Framework. Journal of Multicultural Counseling AndDevelopment, 46(1), 58-73. https://doi.org/10.1002/jmcd.12092

Kaeble, D., Glaze, L., Tsoutis, A., \& Minton, T. (2015). Correctional Populations in the United States, 2014. Bureau of Justice Statistics.

Kapoor, R., Dike, C., Burns, C., Carvalho, V., \& Griffith, E. E. (2013). Cultural competence in correctional mental health. International Journal of Law and Psychiatry, 36 (3-4), 273-280. https://doi.org/10.1016/j.ijlp.2013.04.016

Katz, R. S., Willis, H., \& Joseph, J. J. (2014). Economic inequality, racism and trauma: growing up in racist combat zones and living in racist prisons. Journal of Pan African Studies, 6, 25.

Marbley, A. F., Wimberly, C., Berg, R., Rouson, L., \& Wilkins, E. (2011). Case Studies ofAfrican American Families: Self-Reports of Ethnically Diverse Practitioners. Family Journal, 19(2), 174. https://doi.org/10.1177/1066480711400152

Sue, D. W. (2015). Race talk and the conspiracy of silence: understanding and facilitating difficult dialogues on race. Hoboken: Wiley, 2015.

Tadros, E., \& Finney, N. (2018). Structural Family Therapy With Incarcerated Families. Family Journal, $26(2), 253$. https://doi.org/10.1177/1066480718777409

Trahan, D. P., \& Lemberger, M. E. (2014). Critical Race Theory as a Decisional Framework for the Ethical Counseling of African American Clients. Counseling \& Values, 59(1), 112-124. https://doi.org/10.1002/j.2161-007X.2014.00045.x

Wildeman, C., \& Wang, E. A. (2017). Series: Mass incarceration, public health, and widening inequality in the USA. The Lancet, 389, 1464-1474. https://doi.org/10.1016/S0140-6736(17)30259-3

\section{Copyrights}

Copyright for this article is retained by the author(s), with first publication rights granted to the journal.

This is an open-access article distributed under the terms and conditions of the Creative Commons Attribution license which permits unrestricted use, distribution, and reproduction in any medium, provided the original work is properly cited. 